\title{
The Lethality of COVID-19 for Children with Congenital Heart Disease
}

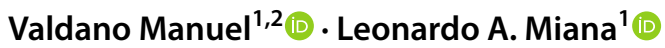 \\ Received: 14 October 2021 / Accepted: 18 November 2021 / Published online: 26 November 2021 \\ (c) The Author(s), under exclusive licence to Springer Science+Business Media, LLC, part of Springer Nature 2021
}

To the Editor,

We welcome and read with great interest the article "Worse Hospital Outcomes for Children and Adults with COVID-19 and Congenital Heart Disease" by Strah et al. [1]. The authors retrospectively analyzed (April 2020-March 2021) 160 children with congenital heart disease (CHD) hospitalized with COVID19 , who accounted for $1.7 \%$ of the total admissions for COVID19 in the Vizient Clinical Data Base and compared with other children with COVID-19 without CHD. In addition to being younger, children with COVID-19 had longer lengths of hospital stay, more complications, high mortality, and higher costs.

The authors state, "to the best of our knowledge, ours is the first national study to demonstrate worse outcomes for children and adults with moderate to severe CHD who are hospitalized for COVID-19." We would like to add that high mortality related to COVID-19 and CHD patients has already been brought to attention.

We have published a multicenter study in Brazil, one of the epicenters of the COVID-19 pandemic [2]. Our survey study which included 46 centers in 22 Brazilian states found that, in addition to the effects broadly reported in the literature [3], such as reduced surgical volume and unbalanced case-mix, there was an increase in mortality among CHD patients infected after repair in the same hospitalization (45.8\%). The aforementioned mortality was not related to CHD risk scores, but mainly to COVID-19 presentation. In Strah et al. study, the mortality rate in CHD patients is almost four times higher than in non-CHD patients $(3.8 \% ; 0.8 \%)$. On the other hand, our findings suggest that postoperative period may play an additional role.

A very interesting observation in the present study is that there was no increment in mortality among adult CHD

Valdano Manuel

valdanympub@gmail.com

1 Division of Cardiovascular Surgery, Heart Institute (InCor), Hospital das Clínicas da Faculdade de Medicina da Universidade de São Paulo, São Paulo, Brazil

2 Cardio-Thoracic Center, Clínica Girassol, Revolução de Outubro Avenue, Second floor, Luanda, Angola patients compared to non-CHD [1]. Maybe CHD acts canceling the protective effect childhood demonstrated in COVID19 disease [4].

Funding None.

Data Availability Not applicable.

Code Availability Not applicable.

\section{Declarations}

Conflict of interest The authors declare that they have no conflict of interest.

Ethical Approval Not applicable.

Consent to Participate Not applicable.

Consent for Publication Not applicable.

\section{References}

1. Strah DD, Kowalek KA, Weinberger K et al (2021) Worse hospital outcomes for children and adults with COVID-19 and congenital heart disease. Pediatr Cardiol 11:1-6. https://doi.org/10.1007/ s00246-021-02751-6

2. Miana LA, Manuel V, Antoniali F et al (2021) COVID-19 pandemic implications in paediatric and congenital heart surgery in Brazil. Cardiol Young 6:1-5. https://doi.org/10.1017/S104795112 1001608

3. Protopapas EM, Rito ML, Vida VL, Sarris GE, Tchervenkov CI, Maruszewski BJ, et al (2020) COVID-19 International congenital heart surgery taskforce early impact of the COVID-19 pandemic on congenital heart surgery programs across the world: assessment by a global multi-societal consortium. World J Pediatr Congenit Heart Surg 11(6):689-696.

4. Shah S, Meenakshisundaram R, Senthilkumaran S, Thirumalaikolundusubramanian P (2020) COVID-19 in children: reasons for uneventful clinical course. Clin Exp Pediatr 63(7):237-238. https://doi.org/10.3345/cep.2020.00801

Publisher's Note Springer Nature remains neutral with regard to jurisdictional claims in published maps and institutional affiliations. 